\title{
What Can Economics Teach us about Santa Claus?
}

\author{
Barna Bakó \\ Research Fellow, MTA-BCE 'Lendület' Strategic Interactions Research Group \\ Assistant Professor, Corvinus University of Budapest, Department of Microeconomics \\ Email: barna.bako@uni-corvinus.hu
}

Péter Isztin

Assistant Professor, Corvinus University of Budapest, Department of Microeconomics

Email: peter.isztin@gmail.com

In this paper we sketch a theory about the role of supernatural beliefs in incentivizing "good" behavior among children by parents. We present a simple theory on the production and the use of certain supernatural beliefs by parents to influence their children's behavior. A prime example of this is the idea of Santa Claus and the idea that Santa Claus rewards children according to how well they have behaved during the year. We show that under standard conditions parents face a time inconsistency problem when trying to incentivize their offspring. We claim that the production of beliefs in certain supernatural or quasi-supernatural persons who allegedly have infinite lives can help parents discipline their children. Finally, we extend this logic to a community and its ruler or rulers. We show that rulers can have incentives to influence the beliefs of their subjects. This incentive is greater whenever the ruler is a monopolist and when he or she expects to rule for a long period. Rulers with limited ability and/or superior technology for producing beliefs will also supply more supernatural stories to enforce their rule.

\section{Keywords: ???}

JEL-codes: ???

\section{Introduction}

In this paper we consider a phenomenon so far not treated rigorously by economists: the phenomenon of Santa Claus. Santa Claus presents us a number of intriguing questions: why do 
children believe in him, why do parents choose to "indoctrinate" children to believe in Santa Claus, why and how is Santa Claus associated with gifts, and more importantly, the withholding of gifts, and finally, how can we make sense of why and when children stop believing in Santa Claus. Are richer or poorer households more likely to experience this phenomenon? What happens when Santa faces competition, from the baby Jesus Christ, for example? This and related puzzles will be discussed in this paper.

The first major theoretical results concerning parental influence on children came from Becker (1991) and Becker and Murphy (2000), who describe the socialization of children by parents in economic terms. In their model, a single parent (a mother) is postulated, for the sake of analytical simplicity and it is assumed that she derives utility from her own consumption as well as the child's consumption. In the model, the parent can influence her and the child's future consumption and therefore her future utility by instilling certain beliefs and preferences on the child. Becker and Murphy (2000) focus on changing preferences. Their justification for this partial deviation from the standard assumption of stable preferences is the common sense notion that children often do not yet have fully-formed stable preferences and that parents as well as peers influence those preferences and so this is worthy of modelling explicitly. In their model, the parent can induce her children to care for her in her old age, thus one motivation for child-rearing is the support one can get from their children later in life. The parent can do this by investing in persuasion or preference formation that produces guilt in the adult child when he or she does not support his or her old age parent, or producing more altruistic feelings within the child. This result has been controversial as it implies parents sometimes knowingly reduce their child's adult utility in order to increase their own consumption, however, such a result comes easily from any setting where parents are not fully altruistic toward their offspring. Similarly, the parent can induce other preferences, beliefs, values that either increase her own consumption or the child's consumption later in life. One such investment can be investing in beliefs or preferences for following certain norms that contribute to the adult child's well-being by making the child more well-adjusted and law-abiding in his or her adult life. Part of this indoctrination can be indoctrinating the child with religious or other magical beliefs. Parents have long tried to pass their own religious beliefs and values on to their children, perhaps because they believe it will serve their child well in either their adult life or in an imagined afterlife.

\section{The basic problem - time inconsistency}

Suppose parents wish to incentivize their offspring to do certain things and not do some others. This incentive from the parents' part can come from selfish as well as altruistic considerations: parents 
may believe (often correctly) that certain behaviors in the present can improve the outcomes of their children later on, while children are too short-sighted to see the benefits. Alternatively, parents might prefer not being bothered by badly behaving children, so they also might have a "selfish" reason to discipline their children. The distinction does matter when it comes to assessing welfare implications, however, in this article we will focus only on how the parent can incentivize "good" behavior. While the parent cares about incentives, she also considers how it directly affects the child's utility, and the costs of rewards and punishments.

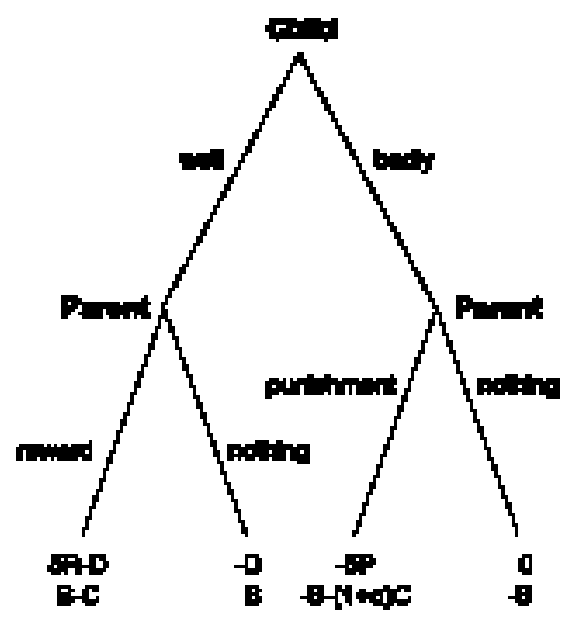

Figure 1. The child-parent game

Consider the following full information game parents and their children play with each other (see Figure 1.). First, the child decides whether to behave well or badly. The parent observes this behavior and decides whether to give out a reward $(\mathrm{R})$ or a punishment $(\mathrm{P})$ for the observed behavior (assuming that parents will never choose to reward their children for bad, or punish their children for good behavior), or whether to do nothing. Suppose that both reward and punishment involves some costs for the parent. These costs could be the opportunity cost of resources, a time cost of the punishment or the reward, or, in the case of punishment, a psychological cost. Let the cost of reward be $\mathrm{C}$ and the cost of punishment be $(1+\alpha) \mathrm{C}$, where $\alpha$ is an exogenous parameter, and — following Becker (1991)'s notation — denotes the extent of parental altruism. Parents receive a payoff $B$ if their child behaves well and a payoff of -B when the child behaves badly. Here we do not consider the problem of whether the parent's utility is derived from selfish or altruistic considerations. We assume that the child has a cost D of good behavior, possibly in the form of unrealized gains from bad behavior and his utility is -D in the case of good behavior if he does not receive any reward for it, and $\delta \mathrm{R}-\mathrm{D}$ if he receives the reward, where $\delta$ is the child's discount factor. 
His utility is 0 if he behaves badly but does not get punished while he gets $-\delta \mathrm{P}$ if he gets punished. Suppose that it is always utility-enhancing for the parent to enforce good behavior, so that B-C $>0$ and $2 \mathrm{~B}-(1+\alpha) \mathrm{C}>0$. Moreover, let us assume that $\delta \mathrm{R}>\mathrm{D}$, so that the reward is sufficient to ensure good behavior.

The unique equilibrium of this game in a one-shot case is that the child behaves badly and the parent does not punish the child. However, we do know that parent-child interactions are typically repeated. In this case the parent can offer the following bargain to the child: I will punish or reward you based on your behavior ever after, and if I fail to live up to my promise, you can punish me by behaving badly. Yet, this repeated parent-child interaction can be best characterized as a finitely repeated game (the parent and the child interact this way as long as the child is dependent on the parent). If the child is rational enough, he knows that in the final round of their repeated interactions the parent has no incentive to reward or punish him, so the cooperation breaks down, not only in the final round but in every period of their interaction.

\section{A possible solution: creating beliefs}

One solution to the above mentioned problem might be to create incentives through persuading individuals of certain supernatural stories.

One example might be the widespread cultural phenomenon of the figure of Santa Claus, named after St Nicholas who is said to distribute presents to children on Christmas Eve (or, in the case of some countries, such as Hungary, on December 6, St Nicholas' Day). It might be the case that parents tell stories about Santa Claus because the consumption of such stories increase the utility of their children. And therefore, if they are altruistic to some extent, it also increases their own utility.

However, there are certain features of Santa Claus-type stories that suggest a (perhaps complementary) alternative explanation, the one that is favored by us in this paper: Santa Claus is said to reward "good" children with more and "bad" children with less or no gifts, or perhaps a gift with negative utility, most often coal (or in Hungary, a birch-rod). Santa Claus seems a good candidate for solving parents' time inconsistency problem above: he is implied to have an infinite life, so he has incentives for reputation-building. He is often depicted as someone who cares about social welfare or justice or a similar goal indicating his impartiality. $\mathrm{He}$ is said to be relatively unconstrained by the laws of physics and said to be perfectly informed about children's behavior or at least claimed to have very low monitoring costs.

More formally, assume, for now, that children believe in the existence of Santa Claus with probability $\theta=1$. Put it differently, they believe with certainty that they are playing a game with 
Santa.

Assume that parents tell the following "story" about Santa's utility function: Santa Claus receives a fraction $\gamma$ of the parent's utility and disutility $\mathrm{B}$ and $-\mathrm{B}$ and incurs a cost $\mathrm{S}$ of distributing gifts where $\mathrm{S}<\mathrm{C}$ as well as $(1+\mu) \mathrm{S}$ for distributing penalties, where $\mu$ can be thought of as the extent of Santa Claus' "altruism" towards children. We assume that the decision of Santa Claus is always binary (he either rewards/punishes or does nothing), and the arguments of his utility function are separable.

Santa's discount factor is $\delta \mathrm{s}>\delta$. His utility when children in each period behave well and do not get rewarded is $\gamma \mathrm{B}+\gamma \mathrm{B} /(1-\delta \mathrm{s}), \gamma \mathrm{B}+(\gamma \mathrm{B}-\mathrm{S}) /(1-\delta \mathrm{s})-\mathrm{S}$ when children behave well and get rewarded, $-\gamma \mathrm{B}-$ $\gamma \mathrm{B} /(1-\delta \mathrm{s})$ when children behave badly and do not get punished, while it is $-\gamma \mathrm{B}+(-\gamma \mathrm{B}-(1+\mu) \mathrm{S}) /(1-\delta \mathrm{s}$ )$-(1+\mu) S$ when children behave badly and get punished. In a one-shot case, Santa never punishes the child and does not reward the child under good behavior, similarly to the parent. However, suppose Santa's action in each period can be observed by children in the next period. Then if Santa rewards and punishes conditionally, he will get a higher utility in the next period, if and only if $2 \delta \mathrm{s}$ $\mathrm{B}-(1+\mu) \mathrm{S}>0$. As he plays the game infinitely, the condition can be rewritten as $2 \mathrm{~B} /(1-\delta \mathrm{s})-(1+\mu) \mathrm{S}>$ 0 . Thus, if Santa Claus is patient enough (a high $\delta$ s) and has low enough reward and punishment cost $\mathrm{S}$ and cares relatively little about short-term disutility of children (a low $\mu$ ), conditional reward and punishment is a best response to good and bad behavior by the child, respectively.

To solve for the equilibrium, consider also the child's problem. A given child in any time period has the same payoffs in each case as in the one-shot and finitely repeated game. Since we assumed earlier that $\delta \mathrm{R}>\mathrm{D}$, a subgame perfect Nash Equilibrium exists in which the child behaves well and Santa Claus rewards the child. The question arises, however, whether the parent has an incentive to play as if she were Santa Claus. In the case when the parent knows for certainty that their interaction ends in the next period, it is obvious that the logic of finitely repeated games kicks in, that is, the parent will deviate from the "reward when good, punish when bad" strategy in the final round. However, if the parent does not know for certain when the last round occurs, the above described equilibrium can be sustained. The intuition behind this is that if the child has behaved well until a given period but the parent deviates from rewarding the child for it, then the child will modify his beliefs about the existence of Santa Claus and therefore will behave badly with a positive probability after the deviation. As we earlier assumed that incentivizing good behavior is utility-increasing for the parent for any given period, the parent has an incentive to maintain the child's belief in Santa Claus. Note that if this modification of the prior probability occurs, then the game becomes a dynamic stochastic game, with some peculiar features that we will discuss in the following section. 


\section{Uncertainty about Santa Claus and comparative statics}

So far we have assumed that children either believe in Santa Claus with certainty or they do not believe in his existence. Naturally, in real life, this is rarely the case among young children. The reason we have not modelled uncertainty is that taking it into account would require us to write a dynamic and stochastic game where one player (the parent) has an alterego, the child believes with some probability that he plays with the parent or the alterego, which then influences the incentives of the parent. This setup would require a pure theoretic foundation, as the problem itself seems novel in the economic/game theoretic literature. The space of this paper does not allow for such a rigorous treatment, so here we only sketch our intuition as to what comparative statics might be derived from a setup with uncertainty about the existence of Santa Claus.

Incentives for supplying beliefs about Santa Claus or similar mythical creatures can depend on the following: if parents are more altruistic, the parent will have lower incentive to punish or not to reward a bad behaving child, so we might expect altruistic parents to spend more resources on creating such beliefs. When alternative means of incentivizing offspring is more costly, we would expect higher reliance on Santa Claus-type stories. We could also expect parents' income to play a role: in poorer families, where children receive less valuable gifts, the prospect of gifts does not constitute such a strong incentive for children than in higher income families. Lower income parents therefore can expect fewer benefits from supplying such stories to their offspring, so we would expect them to rely on other means of disciplining children, such as physical or psychological rewards and punishments more often than higher income parents. Also, if the quality of time spent with children is a normal good, that again reinforces the predicted pattern of richer families relying more on beliefs. We also expect Santa Claus-like stories to be more prevalent in higher income countries. Apart from the above explanation that is based on the need to reward and punish children, we can propose another reason why parents spread certain beliefs among their offspring. When a parent buys an expensive gift for her child, the child might infer the extent of parental altruism as well as the ability of the parent to buy expensive gifts. Parents might wish to avoid signalling both of these in certain situations. They might prefer their children not to know about their income so that they will not beg for more gifts. Under this account, gift-giving can stem not only from altruism or from the need for providing incentives, but also from pressure from the child. If the child knows that the parent is able and willing to buy him expensive gifts, he has an incentive to pressure the parent to do so (by an embarrassing tantrum, for example). A forwardlooking parent might try to avoid such situation by creating a "cover story" for her gift-giving, saying that the gift came not from her, but from, say, Santa Claus. In this account, we would also 
expect higher income parents to rely more on gift giving, as they have more to lose from pressureinduced gift-giving. Because both explanations predict similar patterns, it is hard to disentangle the effects of the two mechanisms. However, given the evidence of the belief in Santa Claus as an incentive-provider, we believe the first mechanism certainly plays a crucial role, with the later one probably having a complementary role. It is important, however, to stress that traditions involving Santa Claus, like all cultural practices, can have multiple possible "functions".

We do have some limited evidence for our intuitions. According to an AP poll performed in the USA in 2006 (Woodward 2006), a higher percentage of children in higher income households believes in Santa Claus than in lower income households. Also, white children are more likely to believe in Santa Claus than black children, though it is unclear how much of the difference can be attributed to income versus other, perhaps cultural factors. The (limited) data so far are consistent with both possible mechanisms described above. Santa Claus is also said to have emerged around the $19^{\text {th }}$ century in Western countries, which again is consistent with our hypothesis that rising incomes increase the demand for Santa Claus related stories through various possible channels. Our comparative statics also predict that as search costs decrease, children will be more likely not to believe in Santa Claus. This explains some of the patterns that we can observe. For instance, many children stop believing in Santa Claus around the time they enter school. One possible explanation for this is that they suddenly acquire more "intellectual maturity". However, to the economist, this explanation is too ad hoc. We find it more likely that as they reach school age, children will interact more with children much older than they are. Older children tend to be better informed for the sheer fact that they have usually spent more time searching for information. If younger children know this, and they also know that fellow children do not have any incentives to make them believe or not believe in Santa Claus, they will interpret their statements as facts increasingly more often than their parents' words, who, while more informed than even older children, have vested interests in influencing their beliefs. When the incentive disadvantage becomes higher than the information advantage on the margin, children will put a higher weight on the opinion of fellow, older children.

\section{Religious persuasion in politics}

Political leaders might use supernatural persuasion for similar reasons as parents sometimes do. ${ }^{1}$ Arguably political leaders also have incentives for propagating certain beliefs among citizens either to promote their private interests or to produce public goods. However, in democratic countries, it is rarely one person who acts as a ruler. In this section we examine how the following considerations influence leaders' incentives to create public goods producing beliefs: whether the country is a

\footnotetext{
${ }^{1}$ More on political persuasion in a different context see Cowen et al. (1994) or Glaeser (2005).
} 
democracy, the intensity of political competition, the expected time the politician is in office, how many people are exercising power, his technology choice set, what technology is available for law enforcement and what technology is available for persuasion, whether, apart from any public good related utility, the leader receives private benefits from law enforcement.

The interpretation of the above considerations is straightforward. The central problem arising in public good provision is free-riding, and so it is with the enforcement of laws. Apart from politicians potentially having the same time inconsistency problem as parents have in disciplining their children, they can also face a free-riding incentive: the individual politician might only be a part of the government machine, so she derives only a fraction of private benefits that the government can get by enforcing laws and also mostly have a lower probability than one of influencing the production of public goods. Also, even if the politician governs alone, she can rarely expect to rule indefinitely, so she is optimizing only to the short run. So our intuition is that the longer a politician stays in her position, the greater effort she will put into supernatural persuasion. Moreover, the fewer decisive politicians there are, the higher incentive they all have in public goods production, including through supernatural persuasion. Suppose that the leader can receive two kinds of benefit: utility from the production of a public good, in our case, law enforcement and some private utility in the form of having a greater chance in retaining leadership. Consider two cases. In the first case the political or leadership market is fully monopolistic, so there is only one leader. The leader internalizes the benefits from public good production as she is necessarily a pivotal agent. However, she probably does not derive much private utility from creating beliefs that support her as a leader against other alternatives, as her power is not threatened anyway. In the second case the leadership is contestable, so the leader cannot act as a monopolist. She engages in limit pricing, or in this case, "limit taxation", to deter entry. Thus, she just breaks even and earns a zero political profit. In such a market, the incumbent leader does not enjoy a monopoly profit so she does not internalize much of the benefits from public good production (she can appropriate only a smaller fraction of newly created wealth). However, she has an incentive in product differentiation. Product differentiation and thus market power can be achieved by persuasion, in our case, by persuading citizens that, for example, the leader has a divine right to rule.

It might seem that we are talking solely about a democracy in this setting, however, our framework can just as easily (and perhaps more realistically) be applied to absolute rule or dictatorship, only in those cases the leader can be dependent on the support of certain influential individuals or interest groups.

\section{Conclusions}


In this paper we have considered the application of basic economic principles to supernatural persuasion within a family context, focusing on the supply and demand for the idea of Santa Claus as a distributor of rewards among children. We have shown how in a one-shot or finitely repeated full information game between parent and child the parent has a basic time inconsistency problem when it comes to incentivizing her offspring. This problem can be overcome with the use of supernatural persuasion. Our outline implies that the use of Santa Claus-type stories increases in household income and in children's information costs, and - mainly due to changing information costs - decreases with children's age. In the final section of the paper we have outlined a possible extension of our basic intuitions to the area of politics, claiming that political leaders can use religious and other supernatural persuasion for enforcing certain norms, which can lead to increasing social welfare but also a social welfare loss when the leader uses persuasion to ensure political rents for herself.

\section{References}

Becker, G. S. (1991): A Treatise on the Family. Cambridge, MA: Harvard University Press.

Becker, G. S. - Murphy, K. M. (2000): Social Economics: Market Behavior in a Social Environment. Cambridge, MA: Harvard University Press.

Cowen, T. - Glazer, A. - McMillan, H. (1994): Rent Seeking Can Promote the Provision of Public Goods. Economics and Politics 6(2): 131-145.

Glaeser, E. L. (2005): The Political Economy of Hatred. Quarterly Journal of Economics 120(1): 45-86.

Woodward, C. (2006): Santa Claus Endures in America. The Washington Post, 23 December. 120(1), pp. 45-86 